Article

\title{
Random Best Proximity Points for $\alpha$-Admissible Mappings via Simulation Functions
}

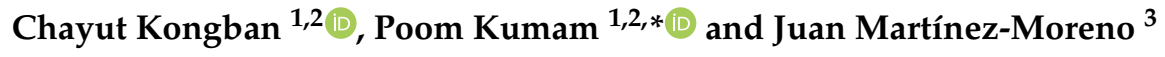 \\ 1 KMUTTFixed Point Research Laboratory, Room SCL 802 Fixed Point Laboratory, \\ Science Laboratory Building, Department of Mathematics, Faculty of Science, \\ King Mongkut's University of Technology Thonburi (KMUTT), 126 Pracha-Uthit Road, \\ Bang Mod, Thrung Khru, Bangkok 10140, Thailand; chayut_kb@hotmail.com \\ 2 KMUTT-Fixed Point Theory and Applications Research Group (KMUTT-FPTA), \\ Theoretical and Computational Science Center (TaCS), Science Laboratory Building, Faculty of Science, \\ King Mongkut's University of Technology Thonburi (KMUTT), 126 Pracha-Uthit Road, Bang Mod, \\ Thrung Khru, Bangkok 10140, Thailand \\ 3 Department of Mathematics, Faculty of Experimental Science, University of Jaén, Campus Las Lagunillas, \\ s/n, 23071 Jaén, Spain; jmmoreno@ujaen.es.com \\ * Correspondence: poom.kum@kmutt.ac.th
}

Received: 29 September 2018; Accepted: 9 November 2018; Published: 18 November 2018 updates

\begin{abstract}
In this paper, we introduce a new concept of random $\alpha$-proximal admissible and random $\alpha$-Z -contraction. Then we establish random best proximity point theorems for such mapping in complete separable metric spaces.
\end{abstract}

Keywords: random best proximity point; simulation function; admissible mapping

\section{Introduction}

Some well known random fixed point theorems are generalizations of classical fixed point theorems. Random fixed point theorems for contraction mapping in a Polish space, i.e., a separable complete metric space, were proved by Špaček [1], Hanš [2,3]. In 1966, Mukhejea [4] proved the random fixed point theorem of Schauder's type in an atomic probability measure space. In 1976, Bharuch-Reid [5] introduced the random fixed point theorems that have been used to establish the uniqueness, existence, and measurability of solutions of random operator equations. In 1977. Itoh [6] extended some random fixed point theorems of Špaček and Hanš for a multivalued contraction mapping in separable complete metric spaces and solved some random differential equations with random fixed point theorems in Banach spaces. In 1984, Sehgal and Waters [7] proved the random fixed point theorem of the classical Rothe's fixed point theorem. After that, many authors have extended, generalized and improved random fixed point theorems in several ways [8-16].

In 2012, Samet et al. [17] introduced a new class of $\alpha-\psi$-contractive type mapping and establish fixed point theorems for such mapping in complete metric spaces. Afterwards, Jleli and Samet [18] introduced a new class of $\alpha-\psi$-contractive type mapping to the case of non-selfmapping and establish best proximity point theorems for such mapping in complete metric spaces. Recently, several authors have investigated the existence and applications of fixed point and best proximity point theorems for $\alpha-\psi$-contractive mapping; see [19-23] and the references therein.

In 2015, Khojasteh et al. [24] introduced the notion of simulation function and proved some fixed point theorem in metric space. Later, Samet [25] and Tchier et al. [26] introduced the best proximity point theorems involving simulation functions. In 2016, Karapinar [27] introduced the notion of $\alpha$-admissible, $\mathcal{Z}$-contraction and proved fixed point theprems in complete metric space. 
In 2017, Karapinar and Khojasted [28] proved the existence of best proximity point theorems of certain mapping via simulation function of complete metric space.

In 2017, Anh [29] introduced the concept of random best proximity point of a random operator. Thereafter, many authors have focused on various existence theorems of random best proximity point; for detail, see [30-32].

Recently, Tchier and Vetro [33] introduced the concepts of random $\alpha$-admissible and random $\alpha-\psi$-contractive mappings and established random fixed point theorems.

The purpose of this paper is to present some random best proximity point theorems for certain mapping via simulation functions in separable metric space.

\section{Preliminaries}

Throughout this paper, let $(M, d)$ be a Polish space, and $(\Omega, \Sigma)$ be a measurable space, where $\Sigma$ is a $\sigma$-algebra of subsets of $\Omega$. Let $U$ and $V$ are two nonempty subsets of $M$. The following notations will be used herein:

$$
\begin{gathered}
d_{\omega}(U, V):=\inf \{d(u(\omega), v(\omega)): u: \Omega \rightarrow U, v: \Omega \rightarrow V, \omega \in \Omega\} ; \\
U_{0}:=\left\{u: \Omega \rightarrow U: d(u(\omega), v(\omega))=d_{\omega}(U, V) \text { for some mapping } v: \Omega \rightarrow V\right\} ; \\
V_{0}:=\left\{v: \Omega \rightarrow V: d(u(\omega), v(\omega))=d_{\omega}(U, V) \text { for some mapping } u: \Omega \rightarrow U\right\} .
\end{gathered}
$$

Definition 1. A mapping $T: \Omega \rightarrow M$ is called $\Sigma$-measurable if for any open subset $N$ of $M$, the set

$$
T^{-1}(N)=\{\omega \in \Omega: T(\omega) \in N\} \in \Sigma .
$$

Notice that when we say that a set $A$ is measurable we mean that $A$ is $\Sigma$-measurable.

Definition 2. A mapping $T: \Omega \rightarrow M$ is called a random operator if $T(\cdot, x)$ is a measurable for any $x \in X$.

Definition 3. A measurable mapping $\xi: \Omega \rightarrow M$ is called a random fixed point of $T: \Omega \rightarrow M$ if

$$
\xi(\omega)=T(\omega, \xi(\omega))
$$

for all $\omega \in \Omega$.

Definition 4. Let $U, V$ be two closed subsets of a Polish space $M$ and $T: \Omega \times U \rightarrow V$ a random operator. A measurable mapping $\xi: \Omega \rightarrow U$ is called a random best proximity point of $T$ if

$$
d(\xi(\omega), T(\omega, \xi(\omega)))=d_{\omega}(U, V),
$$

for any $\omega \in \Omega$.

Clearly, the random best proximity point of a random fixed point of $T$ if $U \cap V \neq \varnothing$. This means that the concept of a random best proximity point is an extension of the concept of random fixed point.

Definition 5. Let $(\Omega, \Sigma)$ be a measurable space, $X$ and $Y$ be two metric spaces. A mapping $h: \Omega \times X \rightarrow Y$ is called Carathéodory if, for all $x \in X$, the mapping $\omega \rightarrow h(\omega, x)$ is $\Sigma$-measurable and for all $\omega \in \Omega$, the mapping $x \rightarrow h(\omega, x)$ is continuous.

Definition 6 ([24]). A simulation function is a mapping $\zeta:[0, \infty) \times[0, \infty) \rightarrow \mathbb{R}$ satisfying the following conditions:

$\left(\zeta_{1}\right) \zeta(0,0)=0$; 
$\left(\zeta_{2}\right) \zeta(t, s)<s-t$ for all $t, s>0$;

$\left(\zeta_{3}\right)$ if $\left\{t_{n}\right\},\left\{s_{n}\right\}$ are sequences in $(0, \infty)$ such that $\lim _{n \rightarrow \infty} t_{n}=\lim _{n \rightarrow \infty} s_{n}>0$, then

$$
\limsup _{n \rightarrow \infty} \zeta\left(t_{n}, s_{n}\right)<0
$$

Denote with $\mathcal{Z}$ the family of all simulation functions $\zeta:[0, \infty) \times[0, \infty) \rightarrow \mathbb{R}$. Due to the axiom $\left(\zeta_{2}\right)$, we have

$$
\zeta(t, t)<0, \text { for all } t>0 .
$$

Denote with $\Psi$ the family of non-decreasing functions $\psi:[0, \infty) \rightarrow[0, \infty)$ satisfying the following conditions:

$\left(i_{1}\right) \psi(t)<t$, for any $t \in \mathbb{R}^{+}$;

$\left(i_{2}\right) \psi$ is continuous at 0 .

Lemma 1 ([34]). Let $(X, d)$ be a metric space and let $\left\{y_{n}\right\}$ be a sequence in $X$ such that $d\left(y_{n+1}, y_{n}\right)$ is nonincreasing and that

$$
\lim _{n \rightarrow \infty} d\left(y_{n+1}, y_{n}\right)=0 .
$$

If $\left\{y_{2 n}\right\}$ is not a Cauchy sequence, then there exist an $\epsilon>0$ and two sequences $\left\{m_{k}\right\}$ and $\left\{n_{k}\right\}$ of positive integers such that the following four sequences tend to $\epsilon$ when $k \rightarrow \infty$ :

$$
d\left(y_{2 m_{k}}, y_{2 n_{k}}\right), d\left(y_{2 m_{k}}, y_{2 n_{k+1}}\right), d\left(y_{2 m_{k}-1}, y_{2 n_{k}}\right), d\left(y_{2 m_{k}-1}, y_{2 n_{k}+1}\right) .
$$

\section{Main Results}

We start with the following definition.

Definition 7. Let $T: \Omega \times M \rightarrow M$ and $\alpha: \Omega \times M \times M \rightarrow[0, \infty)$. We say that $T$ is a random triangular weak- $\alpha$-admissible if

$$
\alpha(\omega, x(\omega), y(\omega)) \geq 1 \text { and } \alpha(\omega, y(\omega), z(\omega)) \geq 1 \Rightarrow \alpha(\omega, x(\omega), z(\omega)) \geq 1,
$$

for all $x, y, z \in M$ and $\omega \in \Omega$.

Definition 8. Let $(\Omega, \Sigma)$ be a measurable space, $(M, d)$ be a separable metric space, $U$ and $V$ are two nonempty subsets of $M, T: \Omega \times U \rightarrow V$ and $\alpha: \Omega \times U \times U \rightarrow[0, \infty)$. We say that $T$ is a random $\alpha$-proximal admissible if

$$
\left.\begin{array}{l}
\alpha(\omega, x(\omega), y(\omega)) \geq 1 \\
d(u(\omega), T(\omega, x(\omega)))=d_{\omega}(U, V) \\
d(v(\omega), T(\omega, y(\omega)))=d_{\omega}(U, V)
\end{array}\right\} \Rightarrow \alpha(\omega, u(\omega), v(\omega)) \geq 1
$$

for all $x, y, u, v \in M$ and $\omega \in \Omega$.

Definition 9. Let $(\Omega, \Sigma)$ be a measurable space, $(M, d)$ be a separable metric space, $U$ and $V$ are two nonempty subsets of $M, \psi \in \Psi$, and $\alpha: \Omega \times M \times M \rightarrow[0, \infty)$. We say that $T: \Omega \times U \rightarrow V$ is a random $\alpha-\psi$-Z $\mathcal{Z}$-contraction with respect to $\zeta \in \mathcal{Z}$ if $T$ is a random $\alpha$-proximal admissible and

$$
\begin{aligned}
& \left.\begin{array}{l}
\alpha(\omega, x(\omega), y(\omega)) \geq 1 \\
d(u(\omega), T(\omega, x(\omega)))=d_{\omega}(U, V) \\
d(v(\omega), T(\omega, y(\omega)))=d_{\omega}(U, V)
\end{array}\right\} \Rightarrow \zeta(d(u(\omega), v(\omega)), \psi(d(x(\omega), y(\omega)))) \geq 0
\end{aligned}
$$

for all $x, y, u, v \in M$ and $\omega \in \Omega$. 
Definition 10. Let $(\Omega, \Sigma)$ be a measurable space, $(M, d)$ be a separable metric space, $U$ and $V$ are two nonempty subsets of $M$, and $\alpha: \Omega \times M \times M \rightarrow[0, \infty)$. We say that $T: \Omega \times U \rightarrow V$ is a random $\alpha$-Z -contraction with respect to $\zeta \in \mathcal{Z}$ if $T$ is a random $\alpha$-proximal admissible and

$$
\left.\begin{array}{l}
\alpha(\omega, x(\omega), y(\omega)) \geq 1 \\
d(u(\omega), T(\omega, x(\omega)))=d_{\omega}(U, V) \\
d(v(\omega), T(\omega, y(\omega)))=d_{\omega}(U, V)
\end{array}\right\} \Rightarrow \zeta(d(u(\omega), v(\omega)), d(x(\omega), y(\omega))) \geq 0
$$

for all $x, y, u, v \in M$ and $\omega \in \Omega$.

Notice that Definition 9 dose not yield Definition 10. Indeed, for $\psi(t)=t$, the implication can be happen but $\psi(t)=t \notin \Psi$.

Definition 11. Let $(\Omega, \Sigma)$ be a measurable space, $(M, d)$ be a separable metric space, $U$ and $V$ are two nonempty subsets of $M$, and $\alpha: \Omega \times M \times M \rightarrow[0, \infty)$. We say that $T: \Omega \times U \rightarrow V$ is a generalized random $\alpha$-Z -contraction with respect to $\zeta \in \mathcal{Z}$ if $T$ is a random $\alpha$-proximal admissible and

$$
\begin{aligned}
& \left.\begin{array}{l}
\alpha(\omega, x(\omega), y(\omega)) \geq 1 \\
d(u(\omega), T(\omega, x(\omega)))=d_{\omega}(U, V) \\
d(v(\omega), T(\omega, y(\omega)))=d_{\omega}(U, V)
\end{array}\right\} \Rightarrow \zeta(d(u(\omega), v(\omega)), r(x(\omega), y(\omega))) \geq 0 \\
& d(v(\omega), T(\omega, y(\omega)))=d_{\omega}(U, V)
\end{aligned}
$$

for all $x, y, u, v \in M$ and $\omega \in \Omega$, with $x(\omega) \neq y(\omega)$, where

$$
r(x(\omega), y(\omega))=\max \left\{d(x(\omega), y(\omega)), \frac{d(x(\omega), u(\omega)) d(y(\omega), v(\omega))}{d(x(\omega), y(\omega))}\right\} .
$$

We can now state the main result of this paper.

Theorem 1. Let $(\Omega, \Sigma)$ be a measurable space, let $(M, d)$ be a Polish space, $U$ and $V$ are two nonempty subsets of $M$ and $\alpha: \Omega \times M \times M \rightarrow[0, \infty)$. Suppose that $T: \Omega \times U \rightarrow V$ is a random $\alpha-\mathcal{Z}$ - -contraction with respect to $\zeta \in \mathcal{Z}$ and $\zeta$ is non-decreasing with respect to second component. The hypotheses are the following:

$\left(A_{1}\right) T$ is a random triangular weak- $\alpha$-admissible,

$\left(A_{2}\right) U$ is closed with respect to the topology induced by $d$,

$\left(A_{3}\right) T\left(\Omega \times U_{0}\right) \subset V_{0}$,

$\left(A_{4}\right)$ there exist measurable mappings $x_{0}, x_{1}: \Omega \rightarrow U$ such that, for all $\omega \in \Omega, d\left(x_{1}(\omega), T\left(\omega, x_{0}(\omega)\right)\right)=$ $d(U, V)$ and $\alpha\left(\omega, x_{0}(\omega), x_{1}(\omega)\right) \geq 1$,

$\left(A_{5}\right) T$ is a Carathéodory mapping.

Then $T$ has a random best proximity point, that is, there exists $\xi: \Omega \rightarrow U$ which is a measurable such that $d(\xi(\omega), T(\omega, \xi(\omega)))=d_{\omega}(U, V)$ for all $\omega \in \Omega$.

Proof of Theorem 1. By hypothese $\left(A_{4}\right)$, we have there exists measurable mapping $x_{0}, x_{1}: \Omega \rightarrow U$ such that $\alpha\left(\omega, x_{0}(\omega), x_{1}(\omega)\right) \geq 1$ and

$$
d\left(x_{1}(\omega), T\left(\omega, x_{0}(\omega)\right)\right)=d_{\omega}(U, V)
$$

for all $\omega \in \Omega$. The hypthese $\left(A_{3}\right)$ implies that $T\left(\omega, x_{1}(\omega)\right) \in V_{0}$, which yields there exists measurable mapping $x_{2}: \Omega \rightarrow U_{0}$ such that

$$
d\left(x_{2}(\omega), T\left(\omega, x_{1}(\omega)\right)\right)=d_{\omega}(U, V)
$$


for all $\omega \in \Omega$. Since $\alpha\left(\omega, x_{0}(\omega), x_{1}(\omega)\right) \geq 1$ and $T$ is a random $\alpha$-proximal admissible, we have that $\alpha\left(\omega, x_{1}(\omega), x_{2}(\omega)\right) \geq 1$. Iteratively, a sequence $\left\{x_{n}(\omega)\right\} \subset U_{0}$ can be constructed as follows:

$$
d\left(x_{n+1}(\omega), T\left(\omega, x_{n}(\omega)\right)\right)=d(U, V), \text { for all } n \in \mathbb{N}_{0}, \omega \in \Omega,
$$

and

$$
\alpha\left(\omega, x_{n}(\omega), x_{n+1}(\omega)\right) \geq 1, \text { for all } n \in \mathbb{N}_{0}, \omega \in \Omega .
$$

If $x_{n}(\omega)=x_{n+1}(\omega)$ for some $n \in \mathbb{N}_{0}, \omega \in \Omega$, then

$$
d\left(x_{n}(\omega), T\left(\omega, x_{n}(\omega)\right)\right)=d\left(x_{n+1}(\omega), T\left(\omega, x_{n}(\omega)\right)\right)=d_{\omega}(U, V),
$$

that is $x_{n}(\omega)$ is a random best proximity point. Assume that

$$
x_{n}(\omega) \neq x_{n+1}(\omega) \text { for all } n \in \mathbb{N}_{0}, \text { for one } \omega \in \Omega .
$$

By combining (1)-(3), we get that

$$
d\left(x_{n}(\omega), T\left(\omega, x_{n-1}(\omega)\right)\right)=d\left(x_{n+1}(\omega), T\left(\omega, x_{n}(\omega)\right)\right)=d_{\omega}(U, V),
$$

for all $n \in \mathbb{N}, \omega \in \Omega$ and

$$
\zeta\left(d\left(x_{n}(\omega), x_{n+1}(\omega)\right), \psi\left(d\left(x_{n-1}(\omega), x_{n}(\omega)\right)\right)\right) \geq 0, \text { for all } n \in \mathbb{N}_{0}, \omega \in \Omega .
$$

Since $T$ is a random $\alpha-\psi-\mathcal{Z}$-contraction with respect to $\zeta \in \mathcal{Z}$. Regarding (3) and $\left(\zeta_{2}\right)$, the inequality (4) yields that

$$
\begin{aligned}
d\left(x_{n}(\omega), x_{n+1}(\omega)\right) & \leq \psi\left(d\left(x_{n-1}(\omega), x_{n}(\omega)\right)\right) \\
& <d\left(x_{n-1}(\omega), x_{n}(\omega)\right),
\end{aligned}
$$

for all $n \in \mathbb{N}, \omega \in \Omega$. It follows that $\left\{d\left(x_{n}(\omega), x_{n+1}(\omega)\right)\right\}$ is a non-increasing sequence bounded below. Then, there exists $r \geq 0$ such that $\left\{d\left(x_{n}(\omega), x_{n+1}(\omega)\right)\right\} \rightarrow r$. We claim that $r=0$. Assume on the contrary that $r>0$. Obviously,

$$
\lim _{n \rightarrow \infty} d\left(x_{n}(\omega), x_{n+1}(\omega)\right)=\lim _{n \rightarrow \infty} d\left(x_{n-1}(\omega), x_{n}(\omega)\right)=r
$$

From $(5)$ and the property $\left(\zeta_{3}\right)$ of simulation function and $\left(i_{1}\right)$ and $\zeta$ is non-decreasing with respect to second component, we get

$$
\begin{aligned}
0 & \leq \limsup _{n \rightarrow \infty} \zeta\left(d\left(x_{n}(\omega), x_{n+1}(\omega)\right), \psi\left(d\left(x_{n-1}(\omega), x_{n}(\omega)\right)\right)\right) \\
& \leq \limsup _{n \rightarrow \infty} \zeta\left(d\left(x_{n}(\omega), x_{n+1}(\omega)\right), d\left(x_{n-1}(\omega), x_{n}(\omega)\right)\right) \\
& <0,
\end{aligned}
$$

which is a contradiction, that is

$$
\lim _{n \rightarrow \infty} d\left(x_{n}(\omega), x_{n+1}(\omega)\right)=0
$$

Next, to prove that $\left\{x_{n}(\omega)\right\}$ is a Cauchy sequence. Suppose, on the contrary, that $\left\{x_{n}(\omega)\right\}$ is not Cauchy sequence. Consequently, there exists $\epsilon>0$ and subsequences $\left\{x_{m_{k}}(\omega)\right\}$ and $\left\{x_{n_{k}}(\omega)\right\}$ of $\left\{x_{n}(\omega)\right\}$, so that for $n_{k}>m_{k}>k$, we have

$$
d\left(x_{m_{k}}(\omega), x_{n_{k}}(\omega)\right) \geq \epsilon
$$


and

$$
d\left(x_{m_{k}}(\omega), x_{n_{k}-1}(\omega)\right)<\epsilon
$$

By Lemma (1), we have

$$
\lim _{k \rightarrow \infty} d\left(x_{m_{k}}(\omega), x_{n_{k}}(\omega)\right)=\lim _{k \rightarrow \infty} d\left(x_{n_{k}-1}(\omega), x_{m_{k}-1}(\omega)\right)=\epsilon .
$$

Since $T$ is a random triangular weak- $\alpha$-admissible, from (2) we have

$$
\alpha\left(\omega, x_{n}(\omega), x_{m}(\omega)\right) \geq 1, \text { for all } n, m \in \mathbb{N}_{0}, \text { with } n>m, \omega \in \Omega .
$$

Thus, we have

$$
\alpha\left(\omega, x_{m_{k}}(\omega), x_{n_{k}}(\omega)\right) \geq 1
$$

and

$$
\begin{aligned}
d\left(x_{m_{k}}(\omega), T\left(\omega, x_{m_{k}-1}(\omega)\right)\right) & =d\left(x_{n_{k}}(\omega), T\left(\omega, x_{n_{k}-1}(\omega)\right)\right) \\
& =d(U, V) \text { for all } k \in \mathbb{N} .
\end{aligned}
$$

Since $T$ is a random $\alpha-\psi-\mathcal{Z}$-contraction with respect to $\zeta \in \mathcal{Z}$, the obtained expression (7) yields the following inequality:

$$
0 \leq \zeta\left(d\left(x_{m_{k}}(\omega), x_{n_{k}}(\omega)\right), \psi\left(d\left(x_{m_{k}-1}(\omega), T\left(\omega, x_{n_{k}-1}(\omega)\right)\right)\right)\right), \text { for all } k \in \mathbb{N} .
$$

Letting $k \rightarrow \infty$ and keeping (6) and $\left(\zeta_{3}\right)$ in mind, and regarding $\left(\zeta_{3}\right),\left(i_{1}\right)$ and $\zeta$ is non-decreasing with respect to second component, we get

$$
\begin{aligned}
0 & \leq \limsup _{n \rightarrow \infty} \zeta\left(d\left(x_{m_{k}}(\omega), x_{n_{k}}(\omega)\right), \psi\left(d\left(x_{m_{k}-1}(\omega), T\left(\omega, x_{n_{k}-1}(\omega)\right)\right)\right)\right) \\
& \leq \limsup _{n \rightarrow \infty} \zeta\left(d\left(x_{m_{k}}(\omega), x_{n_{k}}(\omega)\right), d\left(x_{m_{k}-1}(\omega), T\left(\omega, x_{n_{k}-1}(\omega)\right)\right)\right) \\
& <0
\end{aligned}
$$

which is a contradiction. Thus, we conclude that the sequence $\left\{x_{n}(\omega)\right\}$ is a Cauchy sequence. Since $(M, d)$ is a complete and $U$ is closed subset of $(M, d)$ and $T$ is a Carathéodory mapping, there exists $\xi: \Omega \rightarrow U$ such that

$$
\left\{x_{n}(\omega)\right\} \rightarrow \xi(\omega) \text { as } n \rightarrow+\infty \text { for all } \omega \in \Omega,
$$

it follows that $x_{n}$ is measurable for all $n \in \mathbb{N}$ and

$$
x_{n+1}(\omega)=T\left(\omega, x_{n}(\omega)\right) \rightarrow T(\omega, \xi(\omega)) \text { as } n \rightarrow+\infty \text { for all } \omega \in \Omega .
$$

From (1), (8) and (9) we have

$$
d_{\omega}(U, V)=\lim _{n \rightarrow \infty} d\left(x_{n+1}(\omega), T\left(\omega, x_{n}(\omega)\right)\right)=d(\xi(\omega), T(\omega, \xi(\omega))) .
$$

Therefore $\xi$ is a random best proximity point.

Theorem 2. Let $(\Omega, \Sigma)$ be a measurable space, let $(M, d)$ be a Polish space, $U$ and $V$ are two nonempty subsets of $M$ and $\alpha: \Omega \times M \times M \rightarrow[0, \infty)$. Suppose that $T: \Omega \times U \rightarrow V$ is a random $\alpha-\psi$-Z -contraction mapping with respect to $\zeta \in \mathcal{Z}$ and $\zeta$ is non-decreasing with respect to second component. The hypotheses are the following:

$\left(B_{1}\right) T$ is a random triangular weak- $\alpha$-admissible, 
$\left(B_{2}\right) U$ is closed with respect to the topology induced by $d$,

$\left(B_{3}\right) T\left(\Omega \times U_{0}\right) \subset V_{0}$,

$\left(B_{4}\right)$ there exist measurable mappings $x_{0}, x_{1}: \Omega \rightarrow U$ such that, for all $\omega \in \Omega, d\left(x_{1}(\omega), T\left(\omega, x_{0}(\omega)\right)\right)=$ $d_{\omega}(U, V)$ and $\alpha\left(\omega, x_{0}(\omega), x_{1}(\omega)\right) \geq 1$,

$\left(B_{5}\right) T$ is a sup-measurable,

$\left(B_{6}\right)$ if $\left\{u_{n}(\omega)\right\}$ is a sequence in $U$ such that $\alpha\left(\omega, u_{n}(\omega), u_{n+1}(\omega)\right) \geq 1$ for all $n \in \mathbb{N} \cup\{0\}, \omega \in \Omega$ and $u_{n}(\omega) \rightarrow u_{n}(\omega)$ as $n \rightarrow+\infty$, then there is a subsequence $\left\{u_{n_{k}}(\omega)\right\}$ of $\left\{u_{n}(\omega)\right\}$ with $\alpha\left(\omega, u_{n_{k}}(\omega), u(\omega)\right) \geq 1$ for all $k, \omega \in \omega$.

Then $T$ has a random best proximity point, that is, there exists $\xi: \Omega \rightarrow U$ is a measurable such that $d(\xi(\omega), T(\omega, \xi(\omega)))=d(U, V)$ for all $\omega \in \Omega$.

Proof of Theorem 2. A similar reasoning as in the proof of Theorem 1 gives us that the sequence $\left\{u_{n}(\omega)\right\}$ is a Cauchy sequence. This means that there exists $\xi: \Omega \rightarrow U$ such that $u_{n}(\omega) \rightarrow \xi(\omega)$ as $n \rightarrow+\infty$ for all $\omega \in \Omega$. Due to $\left(B_{2}\right), U_{0}$ is closed. Regarding $\left(B_{3}\right)$, we note that $T(\omega, \xi(\omega)) \in V_{0}$ and hence

$$
d\left(u_{1}(\omega), T(\omega, \xi(\omega))\right)=d_{\omega}(U, V) \text { for some } u_{1} \in U_{0}, \omega \in \Omega \text {. }
$$

Notice that from $\left(B_{6}\right)$, we have

$$
\alpha\left(\omega, x_{n_{k}}(\omega), \xi(\omega)\right) \geq 1 \text { for all } k \in \mathbb{N}, \omega \in \Omega .
$$

Since $T$ is a random $\alpha$-proximal admissible, and

$$
\begin{aligned}
d\left(u_{1}(\omega), T(\omega, \xi(\omega))\right) & =d\left(x_{n_{k}+1}(\omega), T\left(\omega, x_{n_{k}}(\omega)\right)\right) \\
& =d_{\omega}(U, V),
\end{aligned}
$$

we get that $\alpha\left(\omega, x_{n_{k}+1}(\omega), u_{1}(\omega)\right) \geq 1$ for all $k \in \mathbb{N}, \omega \in \Omega$. Therefore,

$$
\zeta\left(d\left(u_{1}(\omega), x_{n_{k}+1}(\omega)\right), \psi\left(d\left(\xi(\omega), x_{n_{k}}(\omega)\right)\right)\right) \geq 0 .
$$

Then $\left(\zeta_{2}\right)$ imples that

$$
\begin{aligned}
d\left(u_{1}(\omega), x_{n_{k}+1}(\omega)\right) & \leq \psi\left(d\left(\xi(\omega), x_{n_{k}}(\omega)\right)\right) \\
& <d\left(\xi(\omega), x_{n_{k}}(\omega)\right)
\end{aligned}
$$

and so

$$
\lim _{k \rightarrow \infty} d\left(u_{1}(\omega), x_{n_{k}+1}(\omega)\right) \rightarrow 0 .
$$

Thus, $u_{1}(\omega)=\xi(\omega)$ for all $\omega \in \Omega$ and (10) we have

$$
d(\xi(\omega), T(\omega, \xi(\omega)))=d_{\omega}(U, V) .
$$

The hypothesis $\left(B_{5}\right)$ that $T$ is sub-measurable implies that $u_{n}$ is measurable for all $n \in \mathbb{N}$ and hence $\xi$ is measurable. Then $\xi$ is a random best proximity point.

Theorem 3. Let $(\Omega, \Sigma)$ be a measurable space, let $(M, d)$ be a Polish space, $U$ and $V$ are two nonempty subsets of $M$ and $\alpha: \Omega \times M \times M \rightarrow[0, \infty)$. Suppose that $T: \Omega \times U \rightarrow V$ is a generalized random $\alpha$ - $\mathcal{Z}$-contraction mapping with respect to $\zeta \in \mathcal{Z}$. The hypotheses are the following:

$\left(C_{1}\right) T$ is a random triangular weak- $\alpha$-admissible,

$\left(C_{2}\right) U$ is closed with respect to the topology induced by $d$,

( $\left.C_{3}\right) T\left(\Omega \times U_{0}\right) \subset V_{0}$, 
$\left(C_{4}\right)$ there exist measurable mappings $x_{0}, x_{1}: \Omega \rightarrow U$ such that, for all $\omega \in \Omega, d\left(x_{1}(\omega), T\left(\omega, x_{0}(\omega)\right)\right)=$ $d(U, V)$ and $\alpha\left(\omega, x_{0}(\omega), x_{1}(\omega)\right) \geq 1$,

$\left(C_{5}\right) T$ is a Carathéodory mapping.

Then $T$ has a random best proximity point, that is, there exists $\xi: \Omega \rightarrow U$ is a measurable such that $d(\xi(\omega), T(\omega, \xi(\omega)))=d_{\omega}(U, V)$ for all $\omega \in \Omega$.

Proof of Theorem 3. By hypothesis $\left(C_{4}\right)$ we have there exists measurable mapping $x_{0}, x_{1}: \Omega \rightarrow U_{0}$ such that $\alpha\left(\omega, x_{0}(\omega), x_{1}(\omega)\right) \geq 1$ and

$$
d\left(x_{1}(\omega), T\left(\omega, x_{0}(\omega)\right)\right)=d_{\omega}(U, V),
$$

for all $\omega \in \Omega$. Hypothesis $\left(C_{3}\right)$ implies that $T\left(\omega, x_{1}(\omega)\right) \in V_{0}$ which yields there exists measurable mapping $x_{2}: \Omega \rightarrow U_{0}$ such that

$$
d\left(x_{2}(\omega), T\left(\omega, x_{1}(\omega)\right)\right)=d_{\omega}(U, V),
$$

for all $\omega \in \Omega$. Since $\alpha\left(\omega, x_{0}(\omega), x_{1}(\omega)\right) \geq 1$ and $T$ is a random $\alpha$-proximal admissible, we have that $\alpha\left(\omega, x_{1}(\omega), x_{2}(\omega)\right) \geq 1$. Iteratively, a sequence $\left\{x_{n}(\omega)\right\} \subset U_{0}$ can be constructed as follows:

$$
d\left(x_{n+1}(\omega), T\left(\omega, x_{n}(\omega)\right)\right)=d_{\omega}(U, V), \text { for all } n \in \mathbb{N}_{0}, \omega \in \Omega,
$$

and

$$
\alpha\left(\omega, x_{n}(\omega), x_{n+1}(\omega)\right) \geq 1, \text { for all } n \in \mathbb{N}_{0}, \omega \in \Omega .
$$

If $x_{n}(\omega)=x_{n+1}(\omega)$ for some $n \in \mathbb{N}_{0}, \omega \in \Omega$, then

$$
d\left(x_{n}(\omega), T\left(\omega, x_{n}(\omega)\right)\right)=d\left(x_{n+1}(\omega), T\left(\omega, x_{n}(\omega)\right)\right)=d_{\omega}(U, V),
$$

that is $x_{n}(\omega)$ is a random best proximity point. Assume that

$$
x_{n}(\omega) \neq x_{n+1}(\omega) \text { for all } n \in \mathbb{N}_{0}, \text { for one } \omega \in \Omega .
$$

By combining (11)-(13), we get that

$$
d\left(x_{n}(\omega), T\left(\omega, x_{n-1}(\omega)\right)\right)=d\left(x_{n+1}(\omega), T\left(\omega, x_{n}(\omega)\right)\right)=d_{\omega}(U, V),
$$

for all $n \in \mathbb{N}, \omega \in \Omega$ and

$$
\zeta\left(d\left(x_{n}(\omega), x_{n+1}(\omega)\right), r\left(x_{n-1}(\omega), x_{n}(\omega)\right)\right) \geq 0, \text { for all } n \in \mathbb{N}_{0}, \omega \in \Omega .
$$

We have

$$
\begin{aligned}
r\left(x_{n-1}(\omega), x_{n}(\omega)\right) & =\max \left\{\frac{d\left(x_{n-1}(\omega), x_{n}(\omega)\right) d\left(x_{n}(\omega), x_{n+1}(\omega)\right)}{d\left(x_{n-1}(\omega), x_{n}(\omega)\right)}, d\left(x_{n-1}(\omega), x_{n}(\omega)\right)\right\} \\
& =\max \left\{d\left(x_{n+1}(\omega), x_{n}(\omega)\right), d\left(x_{n-1}(\omega), x_{n}(\omega)\right)\right\} .
\end{aligned}
$$

Suppose that for some $n_{0}=1,2,3, \ldots$

$$
\max \left\{d\left(x_{n_{0}+1}(\omega), x_{n_{0}}(\omega)\right), d\left(x_{n_{0}-1}(\omega), x_{n_{0}}(\omega)\right)\right\}=d\left(x_{n_{0}+1}(\omega), x_{n_{0}}(\omega)\right) .
$$

On the other hand, since $d\left(x_{n_{0}}(\omega), x_{n_{0}+1}(\omega)\right)>0$, using the property $\left(\zeta_{2}\right)$ of a simulation function, we obtain

$$
\zeta\left(d\left(x_{n_{0}+1}(\omega), x_{n_{0}}(\omega)\right), d\left(x_{n_{0}+1}(\omega), x_{n_{0}}(\omega)\right)\right)<0,
$$


which is a contradiction. As consequence,

$$
r\left(x_{n-1}(\omega), x_{n}(\omega)\right)=d\left(x_{n-1}(\omega), x_{n}(\omega)\right),
$$

for all $n \in \mathbb{N}, \omega \in \Omega$. It means that

$$
\zeta\left(d\left(x_{n}(\omega), x_{n+1}(\omega)\right), d\left(x_{n-1}(\omega), x_{n}(\omega)\right)\right) \geq 0, \text { for all } n \in \mathbb{N}, \omega \in \Omega .
$$

Regarding $\left(\zeta_{2}\right)$, the inequality (14) yields that

$$
d\left(x_{n}(\omega), x_{n+1}(\omega)\right) \leq d\left(x_{n-1}(\omega), x_{n}(\omega)\right) \text { for all } n \in \mathbb{N}, \omega \in \Omega .
$$

Hence, $\left\{d\left(x_{n}(\omega), x_{n+1}(\omega)\right)\right\}$ is a non-increasing sequence bounded below. Then, there exists a $r \geq 0$ such that $\left\{d\left(x_{n}(\omega), x_{n+1}(\omega)\right)\right\} \rightarrow r$. We claim that $r=0$. Assume on the contrary that $r>0$. Taking lim sup of (14) as $n \rightarrow \infty$ and regarding $\left(\zeta_{3}\right)$, we find

$$
0 \leq \limsup _{n \rightarrow \infty} \zeta\left(d\left(x_{n}(\omega), x_{n+1}(\omega)\right), d\left(x_{n-1}(\omega), x_{n}(\omega)\right)\right)<0,
$$

which is a contradiction, that is

$$
\lim _{n \rightarrow \infty} d\left(x_{n}(\omega), x_{n+1}(\omega)\right)=0
$$

Next, to prove that $\left\{x_{n}(\omega)\right\}$ is a Cauchy sequence. Suppose, on the contrary, that $\left\{x_{n}(\omega)\right\}$ is not Cauchy sequence. Consequently, there exists $\epsilon>0$ and subsequences $\left\{x_{m_{k}}(\omega)\right\}$ and $\left\{x_{n_{k}}(\omega)\right\}$ of $\left\{x_{n}(\omega)\right\}$, so that for $n_{k}>m_{k}>k$, we have

$$
d\left(x_{m_{k}}(\omega), x_{n_{k}}(\omega)\right) \geq \epsilon
$$

and

$$
d\left(x_{m_{k}}(\omega), x_{n_{k}-1}(\omega)\right)<\epsilon
$$

By Lemma (1), we have

$$
\lim _{k \rightarrow \infty} d\left(x_{m_{k}}(\omega), x_{n_{k}}(\omega)\right)=\lim _{k \rightarrow \infty} d\left(x_{n_{k}-1}(\omega), x_{m_{k}-1}(\omega)\right)=\epsilon .
$$

Also, by Lemma (1), we have

$$
\lim _{k \rightarrow \infty} d\left(x_{m_{k}-1}(\omega), x_{n_{k}}(\omega)\right)=\lim _{k \rightarrow \infty} d\left(x_{n_{k}-1}(\omega), x_{m_{k}}(\omega)\right)=\epsilon
$$

Since $T$ is a random triangular weak- $\alpha$-admissible, from (12) we have

$$
\alpha\left(\omega, x_{n}(\omega), x_{m}(\omega)\right) \geq 1, \text { for all } n, m \in \mathbb{N}_{0}, \text { with } n>m, \omega \in \Omega .
$$

Thus, we have

$$
\alpha\left(\omega, x_{m_{k}}(\omega), x_{n_{k}}(\omega)\right) \geq 1
$$

and

$$
\begin{aligned}
d\left(x_{m_{k}}(\omega), T\left(\omega, x_{m_{k}-1}(\omega)\right)\right) & =d\left(x_{n_{k}}(\omega), T\left(\omega, x_{n_{k}-1}(\omega)\right)\right) \\
& =d_{\omega}(U, V) \text { for all } k \in \mathbb{N} .
\end{aligned}
$$

Since $T$ is a generalized random $\alpha$ - $\mathcal{Z}$-contraction with respect to $\zeta \in \mathcal{Z}$, the obtained expression (16) yields the following inequality:

$$
0 \leq \zeta\left(d\left(x_{m_{k}}(\omega), x_{n_{k}}(\omega)\right), r\left(x_{m_{k}-1}(\omega), x_{n_{k}-1}(\omega)\right)\right), \text { for all } k \in \mathbb{N} .
$$


Since,

$$
\begin{aligned}
& r\left(x_{m_{k}-1}(\omega), x_{n_{k}-1}(\omega)\right) \\
& =\max \left\{\frac{d\left(x_{m_{k}-1}(\omega), x_{m_{k}}(\omega)\right) d\left(x_{n_{k}-1}(\omega), x_{n_{k}}(\omega)\right)}{d\left(x_{m_{k}-1}(\omega), x_{n_{k}-1}(\omega)\right)}, d\left(x_{m_{k}-1}(\omega), x_{n_{k}-1}(\omega)\right)\right\} .
\end{aligned}
$$

Taking limit from both sides of (17) concludes that

$$
\lim _{k \rightarrow \infty} r\left(x_{m_{k}-1}(\omega), x_{n_{k}-1}(\omega)\right)=\epsilon .
$$

Letting $k \rightarrow \infty$ and keeping (15) and $\left(\zeta_{3}\right)$ in mind, we get

$$
0 \leq \limsup _{n \rightarrow \infty} \zeta\left(d\left(x_{m_{k}}(\omega), x_{n_{k}}(\omega)\right), r\left(x_{m_{k}-1}(\omega), x_{n_{k}-1}(\omega)\right)\right)<0,
$$

which is a contradiction. Thus, we conclude that the sequence $\left\{x_{n}(\omega)\right\}$ is a Cauchy sequence. Since $(M, d)$ is a complete and $U$ is closed subset of $(M, d)$ and $T$ is a Carathéodory mapping, there exists $\xi: \Omega \rightarrow U$ such that

$$
\left\{x_{n}(\omega)\right\} \rightarrow \xi(\omega) \text { as } n \rightarrow+\infty \text { for all } \omega \in \Omega,
$$

it follows that $x_{n}$ is measurable for all $n \in \mathbb{N}$ and

$$
x_{n+1}(\omega)=T\left(\omega, x_{n}(\omega)\right) \rightarrow T(\omega, \xi(\omega)) \text { as } n \rightarrow+\infty \text { for all } \omega \in \Omega .
$$

From (11), (18) and (19) we have

$$
d_{\omega}(U, V)=\lim _{n \rightarrow \infty} d\left(x_{n+1}(\omega), T\left(\omega, x_{n}(\omega)\right)\right)=d(\xi(\omega), T(\omega, \xi(\omega))) .
$$

Therefore $\xi$ is a random best proximity point.

Corollary 1. Let $(\Omega, \Sigma)$ be a measurable space, let $(M, d)$ be a Polish space, $U$ and $V$ are two nonempty subsets of $M$ and $\alpha: \Omega \times M \times M \rightarrow[0, \infty)$. Suppose that $T: \Omega \times U \rightarrow V$ is a random $\alpha$-Z $\mathcal{Z}$-contraction with respect to $\zeta \in \mathcal{Z}$. The hypotheses are the following:

$\left(D_{1}\right) T$ is a random triangular weak- $\alpha$-admissible,

$\left(D_{2}\right) U$ is closed with respect to the topology induced by $d$,

$\left(D_{3}\right) T\left(\Omega \times U_{0}\right) \subset V_{0}$,

$\left(D_{4}\right)$ there exist measurable mappings $x_{0}, x_{1}: \Omega \rightarrow U$ such that, for all $\omega \in \Omega, d\left(x_{1}(\omega), T\left(\omega, x_{0}(\omega)\right)\right)=$ $d_{\omega}(U, V)$ and $\alpha\left(\omega, x_{0}(\omega), x_{1}(\omega)\right) \geq 1$,

$\left(D_{5}\right) T$ is a Carathéodory mapping.

Then $T$ has a random best proximity point, that is, there exists $\xi: \Omega \rightarrow U$ is a measurable such that $d(\xi(\omega), T(\omega, \xi(\omega)))=d_{\omega}(U, V)$ for all $\omega \in \Omega$.

\section{Conclusions}

We introduce the new concept of generalized $\alpha$-Z -contraction, so-called a generalized random $\alpha-\mathcal{Z}$-contraction, in separable metric spaces and also proved its existence theorems in complete separable metric spaces. In particular, our results extend, generalize and improve the results given of Karapinar and Khojasted, in [28].

Author Contributions: All authors read and approved the final manuscript.

Funding: This research was funded by Petchra Pra Jom Klao Doctoral Scholarship for program of King Mongkut's University of Technology Thonburi (KMUTT). 
Acknowledgments: The first author thanks for the support of Petchra Pra Jom Klao Doctoral Scholarship for program of King Mongkut's University of Technology Thonburi (KMUTT). This work was completed while the first author visit Juan Martínez-Moreno at University of Jaén, Jaén, Spain. The authors thank very much Juan Martínez-Moreno for his hospitality and support.

Conflicts of Interest: The authors declare no conflict of interest.

\section{References}

1. Špaček, A. Zufällige gleichungen. Czech. Math. J. 1955, 5, 462-466.

2. Hanš, O. Reduzierende zufällige transformationen. Czech. Math. J. 1957, 82, 154-158.

3. Hanš, O. Random operator equations. In Proceedings of the Fourth Berkeley Symposium on Mathematical Statistics and Probability, Berkeley, CA, USA, 20 June-30 July 1961; Volume 2, pp. 185-202.

4. Mukherjea, A. Random Transformations on Banach Spaces. Ph.D. Thesis, Wayne State University, ProQuest LLC, Ann Arbor, MI, USA, 1967.

5. Bharucha-Reid, A.T. Fixed point theorems in probabilistic analysis. Bull. Amer. Math. Soc. 1976, 82, 641-657. [CrossRef]

6. Itoh, S. A random fixed point theorem for a multivalued contraction mapping. Pac. J. Math. 1977, 68, 85-90. [CrossRef]

7. Sehgal, V.M.; Waters, C. Some random fixed point theorems for condensing operators. Proc. Am. Math. Soc. 1984, 90, 425-429. [CrossRef]

8. Beg, I.; Shahzad, N. Random fixed points of random multivalued operators on Polish spaces. Nonlinear Anal. 1993, 20, 835-847. [CrossRef]

9. Bharucha-Reid, A.T. Random integral equations. In Mathematics in Science and Engineering; Academic Press: New York, NY, USA; London, UK, 1972; Volume 96.

10. Itoh, S. Random fixed point theorems with an application to random differential equations in Banach spaces. J. Math. Anal. Appl. 1979, 67, 261-273. [CrossRef]

11. Lin, T.C. Random approximations and random fixed point theorems for non-self-maps. Proc. Am. Math. Soc. 1988, 103, 1129-1135. [CrossRef]

12. Kumam, P. Random common fixed points of single-valued and multivalued random operators in a uniformly covex Banach space. J. Comput. Anal. Appl. 2011, 13, 368-375.

13. Kumam, P.; Plubtieng, S. Some random fixed point theorems for random asymptotically regular operators. Demonstratio Math. 2009, 42, 131-141.

14. Kumam, W.; Kumam, P. Random fixed points of multivalued random operators with property D. Random Oper. Stoch. Equ. 2007, 15, 127-136. [CrossRef]

15. Kumam, W.; Kumam, P. Random fixed point theorems for multivalued sebsequentially limit contractive maps satisfying inwardness conditions. J. Comput. Anal. Appl. 2012, 14, 239-251.

16. Li, G.; Duan, H. On random fixed point theorems of random monotone operators. Appl. Math. Lett. 2005, 18, 1019-1026. [CrossRef]

17. Samet, B.; Vetro, C.; Vetro, P. Fixed point theorems for $\alpha-\psi$-contractive mappings with applications. Nonlinear Anal. 2012, 75, 2154-2165. [CrossRef]

18. Jleli, M.; Samet, B. Best proximity point for $\alpha-\psi$-proximal contractive type mappings and applications. Bull. Sci. Math. 2013, 137, 977-995. [CrossRef]

19. Hussain, N.; Kutbi, M.A.; Salimi, P. Best proximity point results for modified $\alpha-\psi$-proximal rational contractions. Abstr. Appl. Anal. 2013, 2013. [CrossRef]

20. Karapinar, E.; Kumam, P.; Salimi, P. On $\alpha-\psi$-Meir-Keeler contractive mappings. Fixed Point Theory Appl. 2013, 2013. [CrossRef]

21. Karapinar, E.; Samet, B. Generalized $\alpha-\psi$ contractive type mappings and related fixed point theorems with applications. Abstr. Appl. Anal. 2012, 2012. [CrossRef]

22. Karapinar, E.; Sintunavarat, W. The existence of optimal approximate solution theorems for generalized $\alpha$-proximal contraction non-self mappings and applications. Fixed Point Theory Appl. 2013, 2013. [CrossRef]

23. Salimi, P.; Latif, A.; Hussain, N. Modified $\alpha-\psi$ contractive mappings with applications. Fixed Point Theory Appl. 2013, 2013. [CrossRef] 
24. Khojasteh, F.; Shukla, S.; Radenović, S. A new approach to the study of fixed point theory for simulation functions. Filomat 2015, 29, 1189-1194. [CrossRef]

25. Samet, B. Best proximity point results in partially ordered metric spaces via simulation functions. Fixed Point Theory Appl. 2015, 2015. [CrossRef]

26. Tchier, F.; Vetro, C.; Vetro, F. Best approximation and variational inequality problems involving a simulation function. Fixed Point Theory Appl. 2016, 2016. [CrossRef]

27. Karapinar, E. Fixed points results via simulation functions. Filomat 2016, 30, 2343-2350. [CrossRef]

28. Karapinar, E.; Khojasteh, F. An approach to best proximity points results via simulation functions. J. Fixed Point Throry Appl. 2017, 19, 1983-1995. [CrossRef]

29. Anh, T.N. Random equations and applications to general random fixed point theorems. N. Z. J. Math. 2011, 41, 17-24.

30. Akbar, F.; Kutbi, M.A.; Shah, M.H.; Shafqat, N. Random coupled and tripled best proximity results with cyclic contraction in metric spaces. J. Nonlinear Sci. Appl. 2016, 9, 940-956. [CrossRef]

31. Kongban, C.; Kumam, P. Some random coupled best proximity points for a generalized $\omega$-cyclic contraction in Polish spaces. Fasc. Math. 2017, 59, 91-105. [CrossRef]

32. Okeke, G.A. Best random proximity pair theorems for relatively $u$-continuous random operators with applications. East. Asian. Math. J. 2017, 33, 271-289.

33. Tchier, F.; Vetro, C. Some notes on a second-order random boundary value problem. Nonlinear Anal. Model. Control 2017, 22, 808-820. [CrossRef]

34. Radenović, S.; Kadelburg, Z.; Jandrlić, D.; Jandrlić, A. Some results on weakly contractive maps. Bull. Iranian Math. Soc. 2012, 38, 625-645.

(c) 2018 by the authors. Licensee MDPI, Basel, Switzerland. This article is an open access article distributed under the terms and conditions of the Creative Commons Attribution (CC BY) license (http://creativecommons.org/licenses/by/4.0/). 